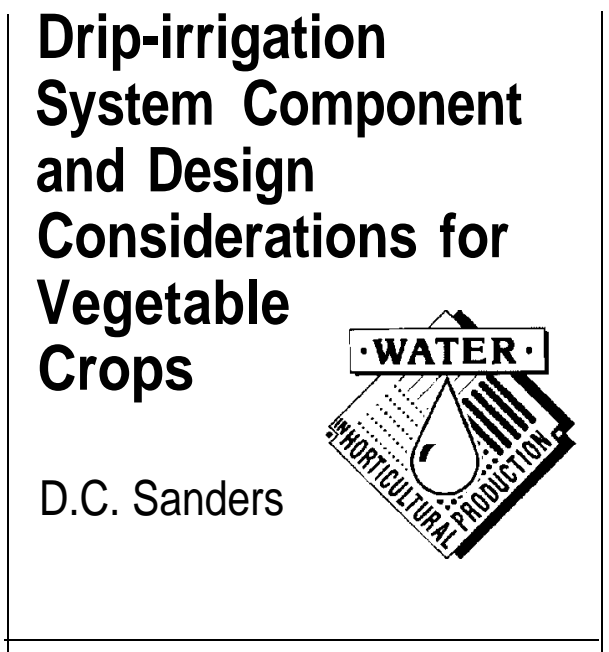

Additional index words. filters, water source, water quality, salinity

Summary. The following should be considered when installing and maintaining a drip irrigation system for vegetable crops: water source (surface or ground water); water quality (salinity, particulate matter, contaminants); size of area to be irrigated; pump size; soil type; drip tape type; crop to be irrigated; management skill of the operator; automation needs; water meter and budget. Use a professional designer.

$\mathrm{T}$ he design of any drip irrigation system must consider several components:

- Water source: surface or ground water

- Water quality: salinity, particulate matter, contaminants

- Size of area to be irrigated; pump size

- Soil type

- Drip-tape type

- Crop to be irrigated

- Management skill of the operator

- Automation requirement

- Backflow prevention

- Water meter

- Budget

Cost should not be the most important factor in making system component choices, because cutting critical cornerscan undermine thesuccess of the system. The various considerations involved in designing a drip irrigation system for vegetable crops are examined below.

Department of Horticultural Science, North Carolina State University, Raleigh, NC 27695-7609

\section{Filter systems}

Water source and quality determine the magnitude of filter requirements. The filter is the heart of a drip irrigation system because clogged emitters will not irrigate properly. If surface water sources are used, sand/media filters are a necessity. These filters remove large pieces of contaminants and very fine microbial contaminants. Sand/ media filters range in diameter from 14 to 48 inches with flow rates of 30 to $625 \mathrm{gal} / \mathrm{min}$ for a pair of filters. Sand filters are paired because one filter is used to backflush the contaminants from the other. One filter is filtering and supplying clean water for the backflushing of the second filter.

It is very important that an adequate water supply be available for backflushing these filters. If stream water is used, a sand separator generally is recommended to remove sand from the water. This reduces the demand on the sand filters and results in a smoother operation. If well water is used, often the filtration job can be done with screen or disk filters. These filters range in piping size from $3 / 4$ inch to 6 inches. They have flow rates of 30 to $700 \mathrm{gal} / \mathrm{min}$. It is a good idea to have screen or disk filters as secondary filters for a sand/media filter system. Sand, screen, or disk filterscan be equipped with automatic back flushing devices. Backflushing should be done when the pressure drop across the filter is $>5$ to $7 \mathrm{psi}$. Good filtration is essential to eliminate clogging of dripper lines. Properand timely backflushing iscritical to trouble-free operation of a drip irrigation system.

\section{Water source}

When well water is used, mineral contaminants in the water that may clog the drip line are a concern. Three of the most common contaminants of well water are $\mathrm{Fe}, \mathrm{S}$, and $\mathrm{Ca}$. The first two can be handled by treating the water. The best advice for operators using wells that have $\mathrm{Ca}$ contamination is to find another water source. Always have the water analyzed before installing a drip irrigation system

\section{System area}

The area to be irrigated at one time is also a major concern. Dividing the total irrigated area into several zones and using automation allows for more efficient use of filtering and pumping facilities.

\section{Pump size}

Pump size is an important consideration in developing a design for a drip system, and it should be tailored to meet the grower's needs. It is advisable to use a professional designer to develop all the specifications for the system. The designer will need to know the distance from the 
water source to the field; the largest size of field to be irrigated at one time; the type of drip tape to be used; the size of piping to the field; the elevation difference between the water source and the highest point in the field; and the type of filters being used. If it is a totally new system, the designer will be able to put together all of these requirements based upon specific needs and physical characteristics of the system components. If the pump is too large, some of the water will have to be bypassed, resulting in increased energy costs. If the pump is too small, adequate water pressure and volume at the field may not be adequate Having a pump that is too small will necessitate using smaller irrigation zones.

\section{Soil type}

Soil type is another important consideration. The wetting pattern can be affected by the rate of water flow in the drip tape and by the soil. In very sandy soils you may wish to use a high flow rate to increase the lateral spread of the wetting pattern. For a clay soil, a very low flow rate may reduce excess spread and surfacerunoff. The flow rate can vary depending on which type of drip tape is used.

\section{Tape type}

Tape type is one of the most critical considerations in designing a drip irrigation system. The flow rate for a particular tape will establish many of the other criteria for system design. There are many tape choices, suppliers, and prices. The reputation of the supplier should be considered in addition to the cost of the material. The drip tape you use is only as good as the service when problems arise. Because the drip system is mechanical, it is likely that problems will occur. Drip tapes can be classified as "laminar flow" (Fig. 1) or "turbulent flow" (Fig. 2). Turbulent flow is a more recent development and has several advantages. Turbulent flow tapes were developed from the technology used for in-line emitters. The turbulent flow materials use the friction generated by water turning a corner to reduce pressure, and thus the path length can be reduced greatly. This turbulent action helps clean emitter paths. Laminar flow tapes allow the water to pass through a small orifice or a group of orifices and flow through a thin path and out an exit orifice or group of orifices. The

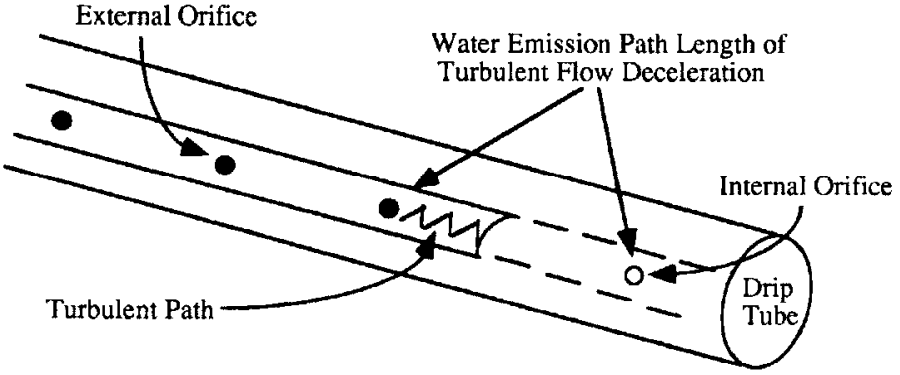

Fig. 2. Cross section of a generalized turbulent flow drip tape.

thin laminar path can be a source of clogging. The laminar type tape relies on friction loss in a relatively long "path length" to reduce pressure. Following are some of the most common tapes on the market and some considerations about each.

laminar flow types

Hardee Biwall, Drip Strip. A cross-linked tough polyethylene tape with an inner and outer chamber. Both chambers are continuous; internal orifices spaced every 3 to $16 \mathrm{ft}, 6 \mathrm{ft}$ being most common internal spacing. External orifices are spaced from 6 to 48 inches. Tubing wall thickness is from 6 to 25 mil. Maximum recommended length of run to maintain $>90 \%$ uniformity is $350 \mathrm{ft}$.

Roberts RoDrip. A tough copolymer plastic with heat-sealed emission path. This tape uses a wide emission path with large inlets and outlets. Internal orifices are spaced every 8 or 12 inches and external orifices are spaced similarly. Tubing wall thickness varies from 5 to 12 mil. Maximum recommended length of run to maintain $>90 \%$ uniformity is $450 \mathrm{ft}$ This tape stretches rather than breaks when excess tension is applied.

\section{Turbulent flow types}

Chapin Turbulent. A tough polyethylene tape available in twin-wall thickness of 4 to 15 mil. Inlet spacing is into a second inner chamber spaced as closely as every 9 inches. Outlet spacings are 9 or 12 inches. Turbulent path length is 9 inches. Maximum recommended length of run to maintain $>90 \%$ uniformity is $350 \mathrm{ft}$ Internal orifice spacing is smaller than the pressure reduction path, thus reducing clogging potential because particles large enough to clog the pressure reduction path are retained in the main tube. Tape may break if it is applied with too much tension on the application reel.

Chapin Cane Turbulent. A tough polyethylene tape available in twin wall thickness of 15 mil Inlet spacing is continuous (as close as every 24 inches) into a second inner chamber. Outlet spacing is 24 inches. Turbulent path is 1 inch. Maximum recommended length of run to maintain $>90 \%$ uniformity is $450 \mathrm{ft}$ Internal orifices are smaller than pressure reduction path thus reducing clogging potential. Tape may break if applied with too much tension.

T-Systems Turbo Tape. Turbo Tape is a tough tape created from a sandwich of polyethylene-polystyrene-

Fig, 1. Cross section of generalized laminar flow drip tape.

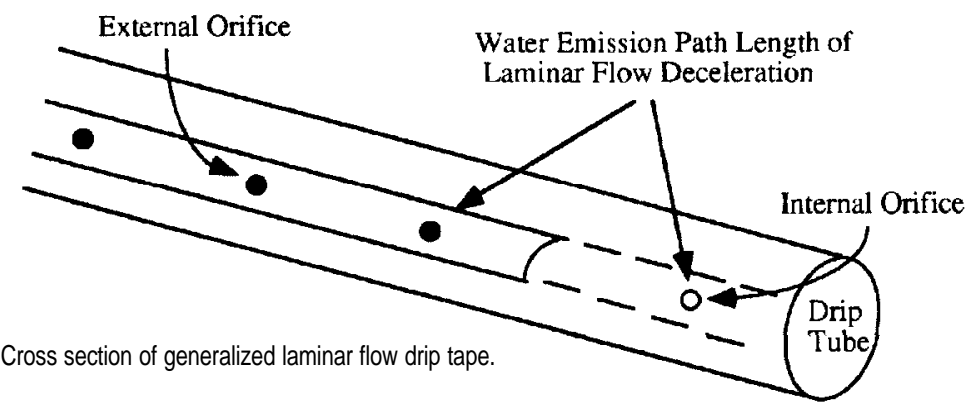

polyethylene available in thickness of 4 to 15 mil. Inlet spacing is as close as every 8 to 16 inches. Outlet spacings are similar. Turbulent path is 8 inches. A seam on the outside of the tape prevents root intrusion. Max imum recommended length of run to maintain $>90 \%$ uniformity is $450 \mathrm{ft}$. Internal orifices are smaller than pressure reduction path thus reducing clogging potential.

Netafim Typhoon. A tough polyethylene available in wall thickness of 10 to 25 mil. Inlet and outlet at each emitter are spaced 16 to 60 inches. Turbulent path is 1 inch. Maximum recommended length of run to maintain $>90 \%$ uniformity is $600 \mathrm{ft}$. Emitter application rate of 0.5 $\mathrm{gal} / \mathrm{h}$ at $15 \mathrm{psi}$. Internal orifices are smaller than pressure reduction path, thus reducing clogging potential. One of the most clog-resistant designs.

Netafim, Ram Tube. The only true pressure-compensating line source tape available. This tubing is reusable for at least 10 years and can be used in rough, undulating terrain. A tough polyethylene tube of $25 \mathrm{mil}$ wall thickness. Inlet spacing at each emitter, and emitters can be spaced 16 to 60 inches. The turbulent path is about 1 inch. An internal bladder on each emitter compensates for pressurechanges. Maximum recommended length of run to maintain $>90 \%$ uniformity is $600 \mathrm{ft}$ Emitter application rate of 0.5 to $1.0 \mathrm{gal} / \mathrm{h}$ at $15 \mathrm{psi}$. Internal orifices are smaller than pressure reduction path, thus reducing clogging potential. One of the most clog-resistant designs available.

All of these tapes will work, but some may perform better than others in a particular application. If a tape is to be reused, ensure that partial clogging has not occurred. A full evaluation of drip tape is presented by Stanley and Clark (1988).

\section{Crop}

The crop to be irrigated will determine the maximum duration of operation required for the system. For instance, strawberries may require 0.1 inch/day, while tomatoes grown in a cool season or watermelons grown in a warm season may require $0.15 \mathrm{inch} /$ day. Warm-season tomatoes and peppers may use 0.4 inch/day. The stage of the crop is important in assigning application amounts, but the system design should be based on peak demand, Do not design a system that will require more than $12 \mathrm{~h} /$ day application time. Workers must sleep, and fatigue leads to mistakes.

\section{Management skills and automation}

Management skills of the operator will critically affect design considerations. If theoperator is willing to learn about time clocks and computers, the design can take advantage of the additional ef- 
ficiency provided by these devices. If the operator is not willing to use these devices, the system must haveadditional safeguards to help reduce operator error. Computers, automatic backflush mechanisms, and zoning solenoids can aid the operator, and they allow for greater system flexibility if the irrigation system is designed properly. However, the system should not be designed to rely solely on these devices, since they do break down and crops always need water.

\section{Backflow prevention}

If fertilizers and/or chemicals are injected into the drip system, most statesand many local municipalities require backflow prevention. These devices ensure that injected materials do not contaminate the water source. Usually, backflow prevention is installed between the injection point and the water source. It includes a check valve, lowpressure drain, vacuum breaker valve, another check valve, and an electric pump interlock. The same sort of backflow prevention is installed between the fertilizer or chemical tank and the injector pump to prevent dilution or overflow of the fertilizer or chemical solution.

\section{Water meter}

A water meter should be a part of the system. The meter can indicate the amount of water being applied. If partial orifice clogging does occur, the operator is quickly aware of the problem.

\section{Budget}

The budget is always a critical part of any design. There may be times when the budget does not allow a safe, functional design for a given acreage. Under these circumstances, the best advice to the designer and grower is to reduce irrigated acreage to fit the budget. Taking design shortcuts to fit a budget can be "Denny wise and pound foolish." A half-grown crop with a poorly designed irrigation system is worse than having no irrigation at all!

A drip irrigation system should be designed by a professional. It is important for the operator to know the essential components, but the professional should be allowed to dot all the "i's" and cross all the "t's". Sometimes the professionally designed system will cost more initially, but the problems and additional expense resulting from poorly designed systems make the expertise of the designer well worth the investment.

\section{Literature Cited}

Stanley, C.D. and G.A. Clark. 1988. Water movement from microirrigation tubing as affected by irrigation rate and scheduling and emission uniformity for line source microirrigation lateral. Rpt. Tomato Res. 1987 and 1988. IFAS, Univ. of Florida. p. 55-67. 